\title{
Staging tourism: Performing place
}

In New Zealand, tourism is tied to images of pristine landscapes into which architecture is admitted as a romanticised diversion from urban places. This project found in the " $100 \%$ Pure New Zealand" tourism marketing campaign-initiated in 1999 (see Tourism NZ, 2019) - an opportunity to speculate on a greater potential for engagement between architecture and tourism. In short, it sought ways that architecture might be truly transformative for tourists.

Through this design research project, the relationship between architecture and the tourist experience was interrogated through increasing scales spanning from an installation to a hotel and finally an artificial island. Instead of attending to tourists as if passive consumers of 'sights/sites', investigated here were the embodied performances tourism makes possible. Architecture in turn was considered a stage for amplifying this performative dimension, with places themselves thought of as performances en route; rather than as fixed and incompatible with the hypermobility of tourism.

\section{Mobilising the tourist}

The project was shaped by two key theoretical shifts in how tourism is understood from an architectural perspective. The first sought to recognise tourism and architecture as reciprocally related. Hence the project built on the proposition that rather than being a backdrop to tourist experiences, architecture was thought as integral to these experiences (Ockman and Fraustro, 2005: 35). As such, architecture can be seen to build on tourist values to the extent that tourism sites are often redesigned and packaged for mass consumption (Lasansky, 2004: 1). This understanding signals that tourism is simultaneously a process through which places are experienced and a force which shapes and interprets those places.

The second theoretical shift looked to tourism studies to better rethink the presumption that tourism and the 'tourist gaze' are essentially passive (Urry, 1992: 172). Tourism was instead understood as a dynamic practice that is 'performed', and that architecture may amplify the multi-sensuous experiences deepening this performance of tourism. This emphasis on performance enabled a sensitivity to the way tourists inscribe themselves into space through social practices, (re) 


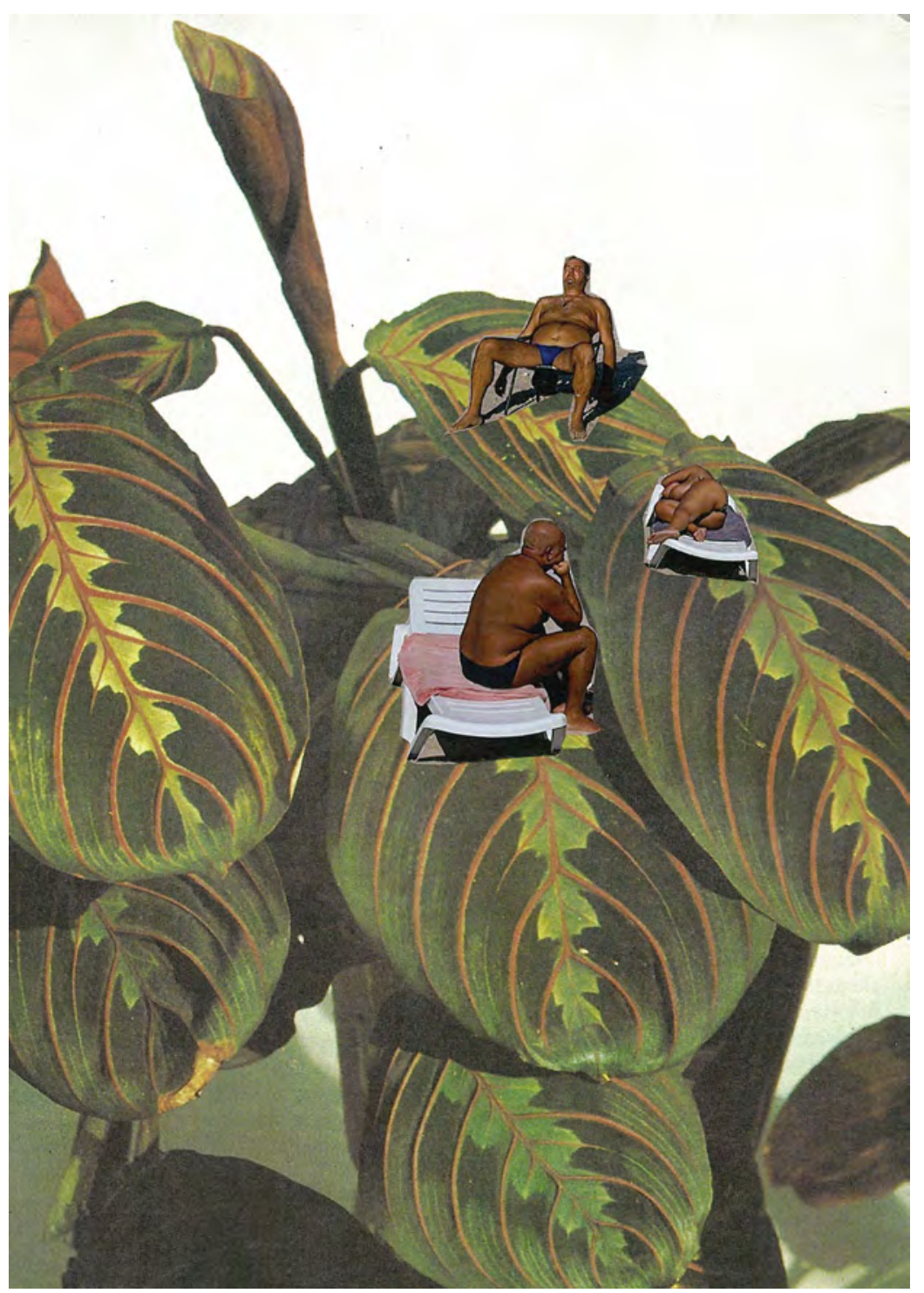

Fig. 1 Author (2016). Preliminary investigations into understanding the tourist through performance [Photographic collage] producing place through their individual and collective enactments. Attentive to the practice of 'doing tourism', this project considered a series of staged performances, choreographed through architecture as a mise-en-scene or theatricalising platform. Drawing from both these theoretical threads, the project positioned architecture as central to the tourist experience and asked, how can architecture stage and amplify the embodied performances of tourism?

\section{Expanding "Wellywood"}

The investigation is sited in Shelly Bay, a former military base and emerging recreation hub along the coastline of the Miramar Peninsular in Wellington, New Zealand. The decision to focus the project around Shelly Bay came about before the announcement of a new, proposed $\$ 500$ million-dollar development for the area. This development aimed to consolidate Shelly Bay as a burgeoning tourism hub on the periphery of the central city, one just $3 \mathrm{~km}$ from Wellington Airport. The site is also adjacent to the popular movie tour route which operates in the area; it's close to Weta Workshop and various nearby shooting locations for the 
Fig. 2 Author (2016). Wellington Harbour [Photographic collage]

Lord of the Rings trilogy. Parodically dubbed "Wellywood" in recognition of the centrality of film production for the capital's economy, the title similarly offers a marketing platform for the film-based tourism underpinning Wellington's tourism overall-a dominance that itself forces a re-examination of appeals to "authentic" tourist experiences typically associated with New Zealand (Tzanelli, 2004: 38). For the relationship between the Shelly Bay site and Wellington's urban placement overall, see Figure 2.

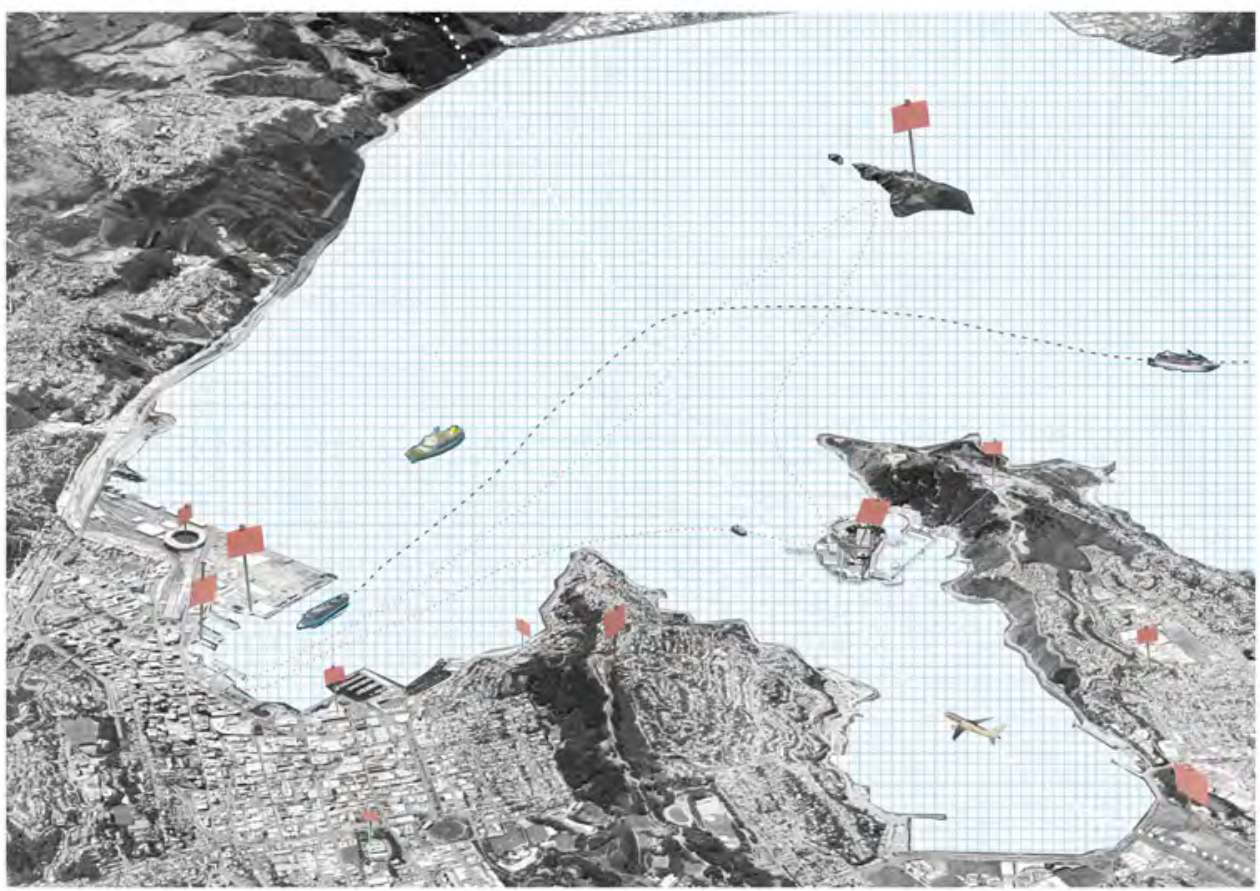

\section{Shifting scales}

To explore the relationship between architecture and tourism, a "design through research" methodology was employed where the design proposition developed through iterative experiments at increasing scales. In summary, three scales were explored: the first engaging with the human scale and culminated in a 1:1 installation; the second explored the performance of tourism through the design of a hotel; and the third proposed an artificial island to stage a range of public performances by tourists. Working through these shifting scales allowed a critical revaluation of the proposition across different design registers.

In more detail, the first design scale exploration extracted moments of interest from the Shelly Bay site and developed multiple scenarios through drawings and physical modelling (Fig. 3). Each of these experimental scenarios sought notions of place that incorporated movement and displacement. These qualities were translated into a series of physical objects in order to create a 1:1 installation (Fig. 4).

Following these early experiments into fluid notions of place, site and placement, architecture and the performance of tourists were more directly engaged with and tested via the design of a hotel, itself thought of as a stage for "dwelling in mobilities". This staged environment in fact offered revised potential for amplifying the corporeal, tactile experiences of tourists (Penner, 2004: 219). 

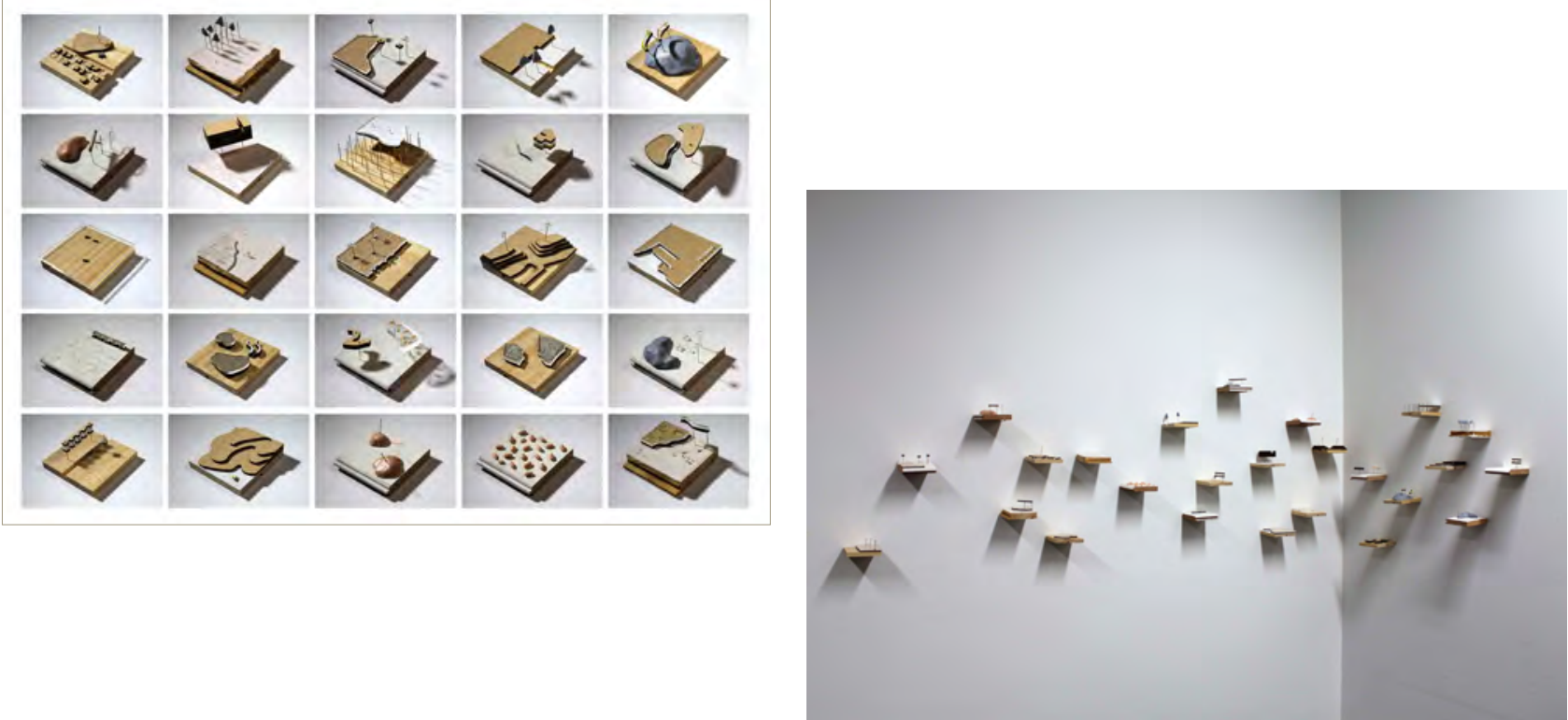

Fig. 3 Author (2016). Explorations of site movement and displacement [Photograph of physical models]

\section{Fig. 4 Author (2016). Physical} models formed as 1:1 installation [Photograph of physical models]

Fig. 5 Author (2016). Performing tourism within the hotel [Composite digital images]
The hotel programme was employed as a tool to interrogate the usual partition of exotic and everyday aspects of the tourist experience. While hotels traditionally leave little room for the intersection of everyday routines with socially exuberant experiences - with private rooms divided from spaces of social interaction - in this experiment the hotel was designed to intersect socially exuberant performances with everyday routines to better encourage new "encounters, and opportunities for action" (Dovey and Dickson, 2002: 5). To do this, private spaces were made to continuously brush up against lively social spaces allowing the privatised routines of dwelling to be performed simultaneously with the dynamic mobilities associated with 'doing tourism' (Fig. 5 and 6).

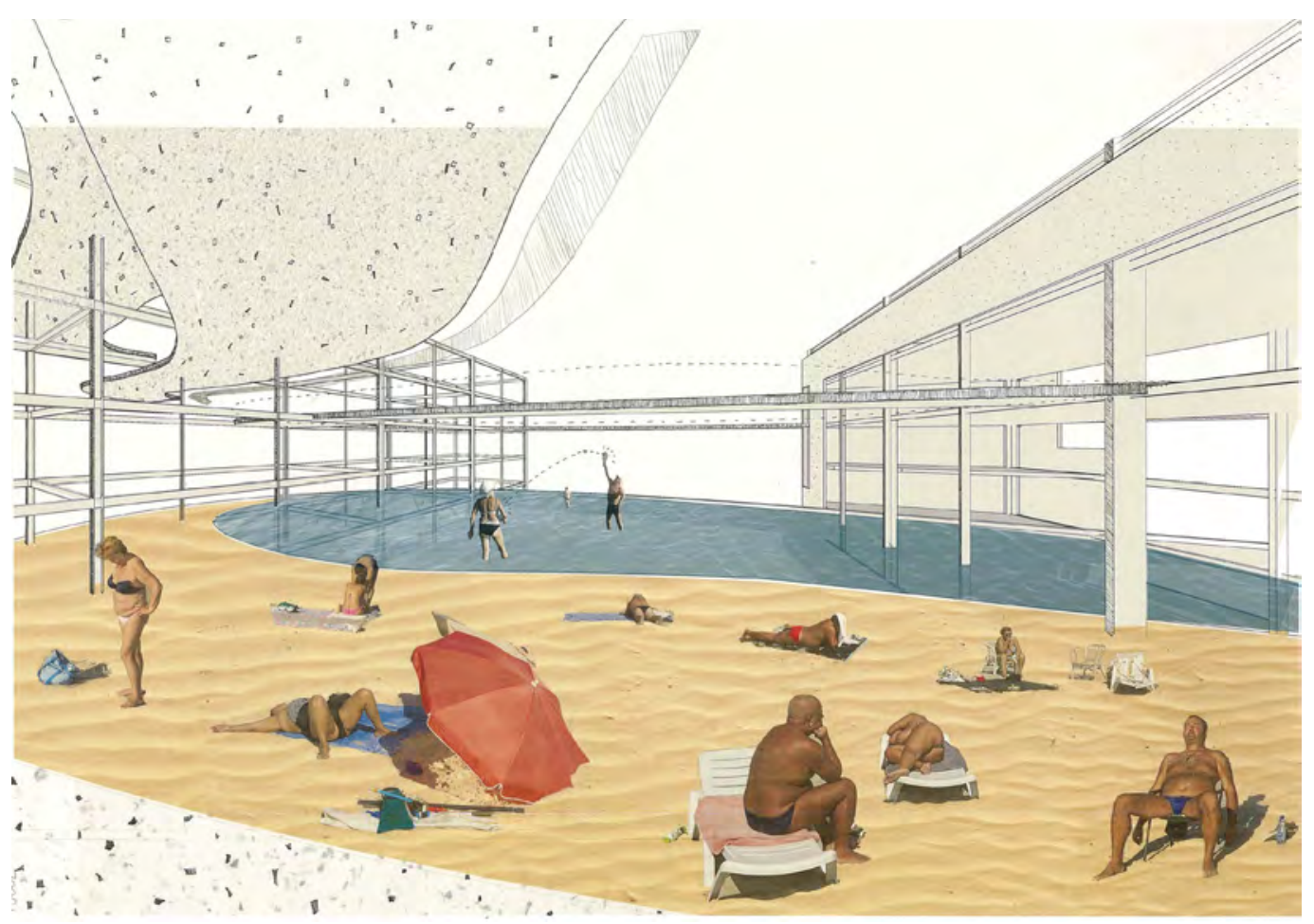


Fig. 6 Author (2016). Performing tourism within the hotel

[Composite digital images]

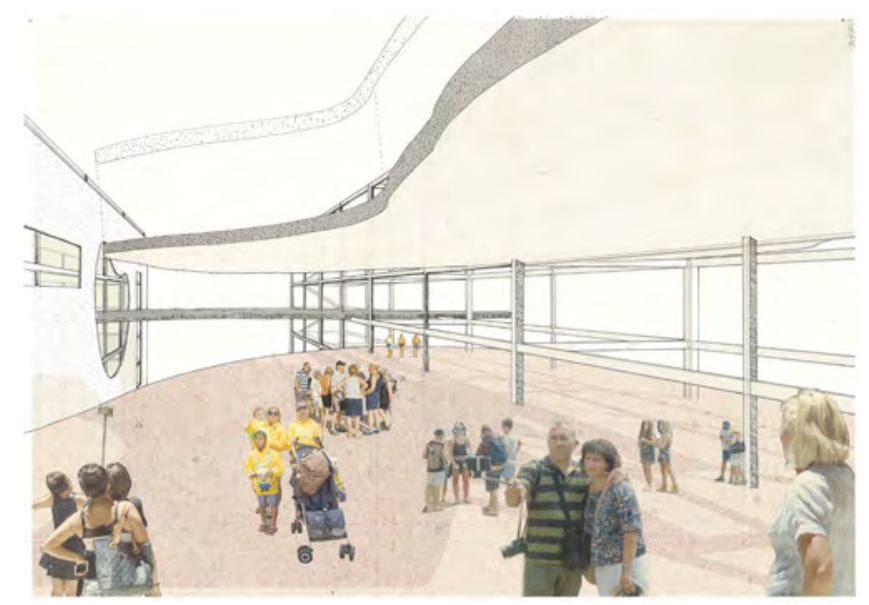

In the final stage of the project, the design of an artificial island offered a mise-enscene for investigating parodically the placemaking capacity of tourists through their individual and collective performances. The artificial island was located just off the shoreline of Shelly Bay and utilised surplus land dredged from Wellington Harbour for the proposed airport runway extension (Figs. 7 and 8).

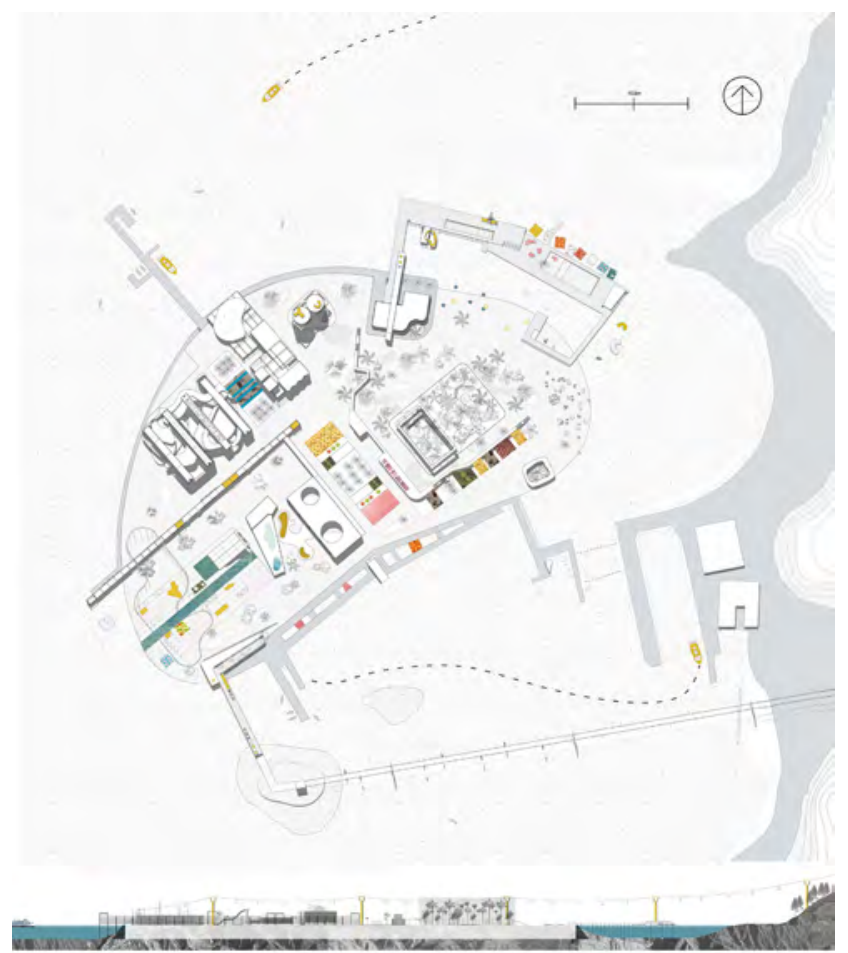

Fig. 7 Author (2016). Masterplan of the artificial island [Composite digital image]

Fig. 8 Author (2016). Axonometric view of the artificial island [Composite digital image]

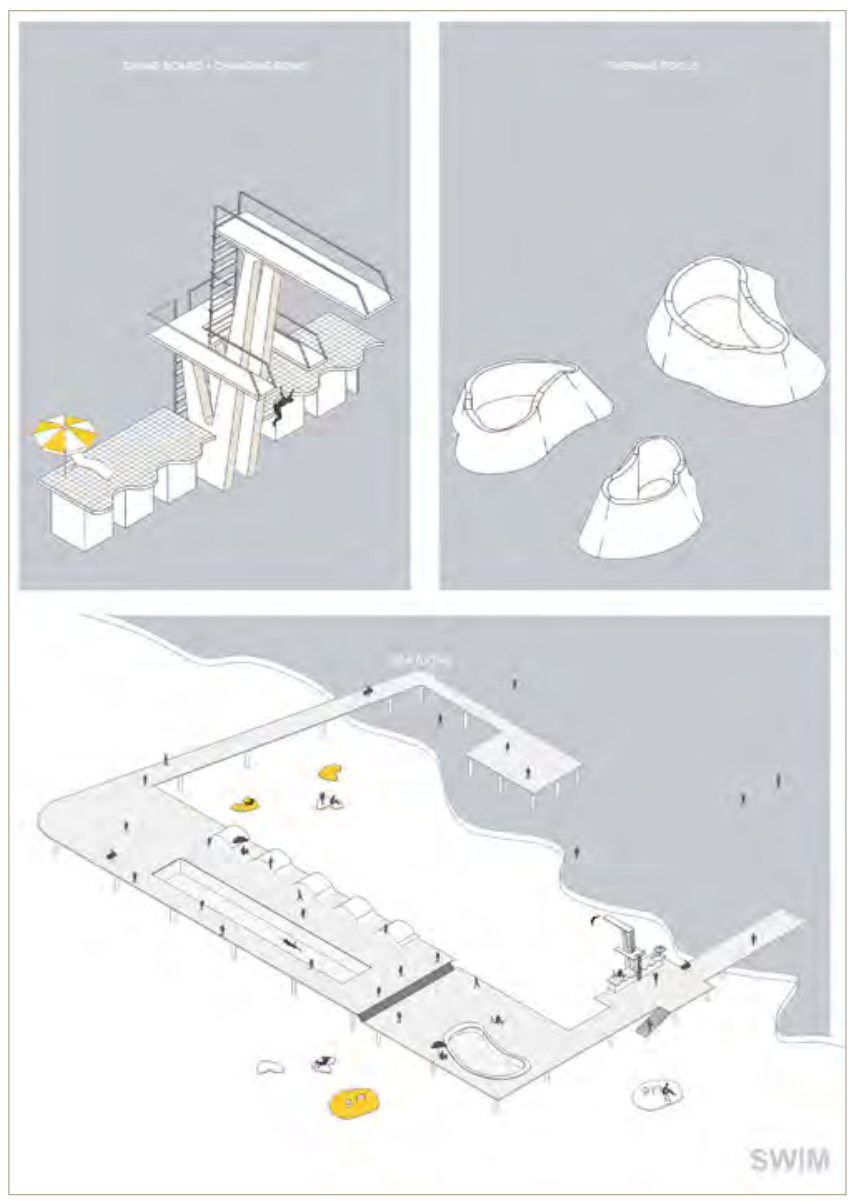




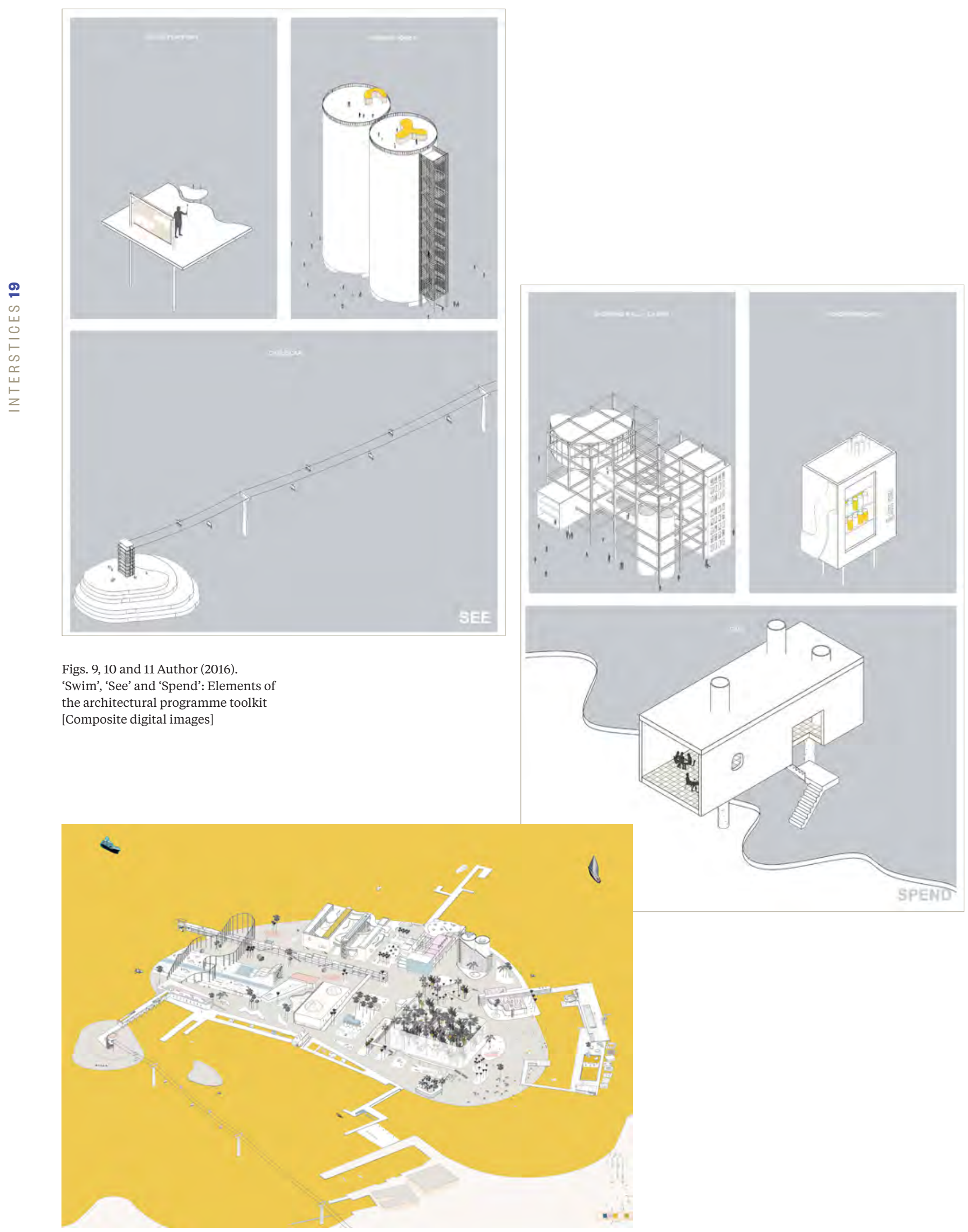


Acts of relaxing, playing, sightseeing and spending were programmed into the island's design through architectural gestures which invited the site to be used in multiple, intersecting ways thereby amplifying the performative nature of the enactments. A series of 'architectural toolkits' resulted. For instance, the 'swim toolkit' incorporated a diving board, thermal pools and sea baths which asserted the corporeal qualities of being in and with water. Fountains heightened 'eruptive' and 'splashing' experience, while bobbing pontoons asserted floating sensations. These toolkits supported the notion of tourism as a dynamic practice integral with its enabling architecture. Through their participation in these social practices, tourists were imagined to inscribe themselves into space and (re) produce places eventfully via their individual and collective performances (Figs. $9,10,11,12$ and 13$)$.

To conclude, this project sees architecture as a central protagonist in developing an understanding of tourism through design, a proposition that situates the tourist not as a passive consumer of places but as "a dynamic force in creating them" (Crang, 1997: 74). As such, this design research project asserts that while the performances of tourists can be staged through architectural mis-en-scene, tourists themselves produce place through their individual and collective performances. Consequently, neither tourism nor place can be assessed as merely products; instead, their intertwining incessantly performs places.
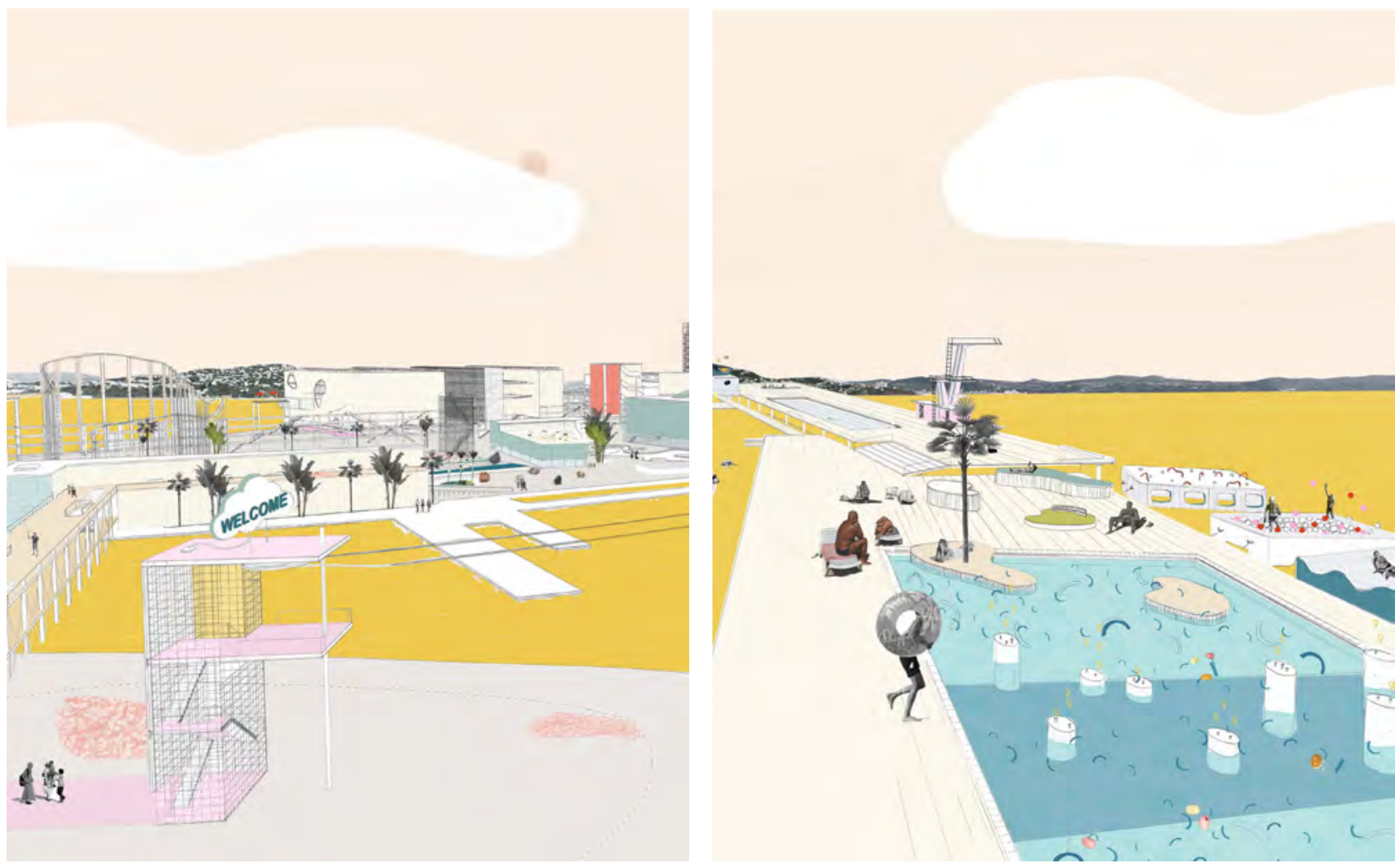

Figs. 12 and 13 Author (2016). View of the island's main public entrance via the gondola, and view of the heated sea baths [Composite digital images] 


\section{REFERENCES}

Crang, M. (1997). Picturing

practices: Research through the tourist gaze. Progress in Human Geography, 21(3), 359-373.

Dovey, K. \& Dickson, S. (2002).

Architecture and freedom? Programmatic innovation in the work of Koolhaas/OMA. Journal of Architectural Education, 56(1), 4-13.

Lasansky, D. M., \& McLaren, B. (2004). Architecture and tourism: Perception, performance, and place. Oxford, UK \& New York, NY: Berg.

Ockman, J. \& Frausto, S. (Eds.) (2005). Architourism. Authentic, escapist, exotic, spectacular. Munich: Prestel.

Penner, B. (2004). Doing it right: Postwar honeymoon resorts in the Pocono Mountains. In Lasansky, D. M. \& McLaren, B. (Eds.), Architecture and tourism: Perception, performance and place. Oxford, England \& New York: Berg.

Rendell, J. (2013). A way with words: Feminists writing architectural design research. In M. Fraser (Ed.), Design research in architecture: An overview. Surrey, UK: Ashgate Publishing.

Tourism New Zealand (2019). 100\% Pure New Zealand. Retrieved from, https://www. tourismnewzealand.com/about/ what-we-do/campaign-andactivity/.
Tzanelli, R. (2004). Constructing the 'cinematic tourist': The 'sign industry' of The Lord of the Rings. Tourist Studies, 4(1), 21-42.

Urry, J. (1992). The tourist gaze 'revisited'. American Behavioral Scientist, 36(2), 172-186. 